\title{
Implementation of Inclusive Education Practices for Children with Disabilities and Other Special Needs in Uganda
}

\section{John Baptist Okech ${ }^{1}$ Imam Yuwono ${ }^{2}$ Wamaungo Juma Abdu ${ }^{3 \times}$}

${ }^{\prime}$ Department of Special Needs Studies, Faculty of Special Needs and Rehabilitation, Kyambogo University, Kyambogo, Uganda.

Email:jbokech@kyu.ac.ug

${ }^{\circ}$ Department of Special Needs Education, Faculty of Education and Teacher Training, Universitas Lambung Mangkurat, Banjarmasin, South Kalimantan, Indonesia.

Email:imam.plb@ulm.ac.id

${ }^{s}$ Department of Adult and Community Education, Faculty of Special Needs and Rehabilitation, Kyambogo University, Kyambogo, Uganda.

Email:jwamaungo@kyu.ac.ug



( Corresponding Author)

\section{Abstract}

This study aimed to assess the factors that influence the effective implementation of inclusive education, taking into consideration learners with disabilities and other special needs. The study objectives focused on the following key aspects that directly influence the implementation of inclusive education: inclusive policies, attitudes, perceptions, curriculum issues, and learning environment. The study adopted a case study design and employed qualitative approaches in sampling. Participants of the study $(\mathrm{N}=103)$ included special needs teachers $(\mathrm{N}=73)$ and learners with disabilities $(\mathrm{N}=30)$. Data collection was carried out through interviews. Some of the findings were positive, namely the policies on inclusive education were reported to be clear and well-suited to guiding the implementation practice, although some stakeholders were reported to be less committed. Attitudes towards learners with disabilities and other special needs were reported to be increasingly positive in the last decade. The findings on the perceptions of the ability and capability of learners with disabilities and other special needs to benefit from inclusive education drew a mixed reaction - some respondents reported that there were learners who were able to benefit from inclusive settings, while others were not. On the subject of the curriculum, the results revealed that some learners with disabilities and other special needs were capable of benefiting from the regular curriculum, while others would benefit from a special curriculum. Lastly, with regards to environmental factors, the study revealed that adequate preparations were always made to provide a conducive environment for learning in inclusive education settings. A major recommendation was made to draw the attention of policy makers to support inclusive education, which ought to be treated as a right and not a privilege for learners with disabilities and other special needs.

Keywords: Inclusive education, Learners with disabilities, Other special needs, Uganda, Inclusive policies, Attitudes, Perceptions, Curriculum, Learning environment, Implementation.

Citation John Baptist Okech; Imam Yuwono; Wamaungo Juma Abdu (2021). Implementation of Inclusive Education Practices for Children with Disabilities and Other Special Needs in Uganda. Journal of Education and e-Learning Research, 8(1): 97-102.

History:

Received: 24 July 2020

Revised: 14 December 2020

Accepted: 18 January 2021

Published: 8 February 2021

Licensed: This work is licensed under a Creative Commons

Attribution 3.0 License $(\mathrm{cc})$

Publisher: Asian Online Journal Publishing Group
Acknowledgement: All authors contributed to the conception and design of the study.

Funding: This study received no specific financial support.

Competing Interests: The authors declare that they have no conflict of interests.

Transparency: The authors confirm that the manuscript is an honest, accurate, and transparent account of the study was reported; that no vital features of the study have been omitted; and that any discrepancies from the study as planned have been explained.

Ethical: This study follows all ethical practices during writing. 
Contents

1. Introduction

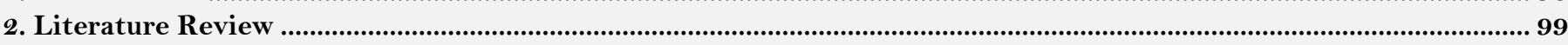



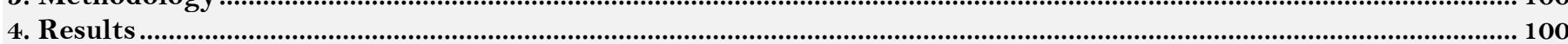



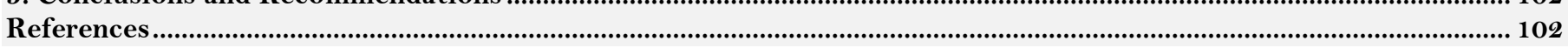

\section{Contribution of this paper to the literature}

This study will help to enhance the effective implementation of inclusive education, taking into consideration disability issues. In regard to environmental factors, the study reveals that adequate preparations are required to provide a conducive environment for learning in inclusive settings. The paper proposes a need for support from all stakeholders to treat inclusive education as a right and not a privilege for learners with disabilities and other special needs.

\section{Introduction}

This study aims to assess the factors that influence the effective implementation of inclusive education for learners with disabilities and other special needs. Historically, people with disabilities and other special needs in most, if not all, countries around the world have faced discrimination in the provision of education. When education has been made available to them, they have typically been subjected to special segregated forms of education due to the nature of their impairment or their mental or behavioral characteristics. It was not until 1994, under the auspices of the United Nations Educational Scientific and Cultural Organisation (UNESCO) (1994) that countries around the world committed themselves, through the Salamanca Declaration, to embracing inclusive education. Uganda, as a signatory to the aforementioned declaration, has accordingly since that time been obliged to implement inclusive education practices. Currently, in Uganda, inclusion is the core of the reform agenda for disability development under the National Vision $2040(2000-2040)$. The reform agenda has hitherto emphasized the reduction of inequality through, among other measures, bringing The Uganda Equal Opportunities Commission (EOC) Act of 2007 into force, to ensure that equality compliance is implemented across all sectors, including those recommended as per the Government of Uganda Public Finance Management (PFM) Act of 2015. The National Planning Authority (NPA) has therefore developed National Disability Inclusive Planning Guidelines to provide direction for the planning, budgeting, and monitoring of harmonized disability interventions in Uganda for persons with disabilities. According to NPA, about $13 \%$ of the population of Uganda has a disability. The government thus recognizes disability as a cross-cutting issue that is relevant to all sectors and at all levels (national and local) and must be addressed as such in development plans, and in all activities.

Whether they are aware of it or not, it is these development plans, inter alia, that guide planners in the education sector to create and implement effective and beneficial inclusive education practices for learners with disabilities and other special needs in Uganda. The reason for educators to do this, as argued by Oswald and Swart (2011), is that inclusion enables learners with disabilities and other special needs to enjoy the inalienable rights to fully benefit from their school experiences, by learning alongside ordinary pupils while getting the necessary support. Richy and Wheeler (2016) are among those who advocate for inclusion, pointing out the need to enhance inclusion and recommending that only learners with severe impairments should be referred to special schools to receive special and unique support there. The question of whether or not the inclusive education goal is achievable in Uganda has, according to Samkange (2013), raised a heated debate among parents, special needs education teachers, and other relevant stakeholders. The point of contention, as viewed by Samkange, hinges on the interpretation of inclusion, which causes confusion for some stakeholders as it requires that learners with disabilities and other special needs attend mainstream classes irrespective of their impairment, ability, and age.

The confusion with regards to the strengths and weaknesses of inclusion and how best to implement it can be traced to the way it is defined by different authorities and individuals. The United Nations Girls Education InitiativeUNGEI (2017) for one, defines inclusive education as a system that functions to address different categories of learners, while emphasizing their varying needs through increased participation in learning, culture, and communities, thereby reducing exclusion in education. For this to be achieved, Scherman, Zimmerman, Howie, and Bosker (2014) add that the curriculum must be adapted with significant changes in content, approaches, structures, and strategies. Scherman et al. (2014) further advise that for inclusive education to succeed, all concerned parties ought to share responsibilities at their different levels. According to Scherman et al. (2014) sharing responsibilities involves, among other things, proactively identifying the barriers and obstacles learners encounter when they participate in learning. This assertion is supported by UNESCO (2013) which affirms that inclusive education is a process that helps learners to overcome barriers which limit their participation in and achievement of successful learning. Supporting a similar interpretation of inclusive education, Starczewska, Hodkinson, and Adams (2012) contend that inclusive education creates a chance to increase the participation of diverse learners, including learners with disabilities and other special needs, and that it necessitates revisiting the pertinent cultures, policies, and practices. Louw and Wium (2015) support this view and point out that there are many marginalized learners worldwide who do not have the chance to attend school. As enumerated above, there are various reasons for implementing inclusive education in Uganda, as well as in other parts of the world. While the implementation of inclusive education is desirable, there are numerous obstacles that impede success in that direction. The Ugandan government launched the disability reform agenda under the National Vision 2040 in 2000, meaning that by the end of that period all the objectives set therein are to have been fully achieved. Half of that period has already passed, meaning that there are only 20 years remaining to achieve the objectives. The question that remains to be answered is, how many of the disability-related goals have already been achieved? This study aims to examine the key aspects that are believed to impact on either the success or failure of the implementation of inclusive education. These include policies, attitudes, perceptions, curriculum issues, and learning environment. 


\section{Literature Review}

\subsection{Inclusive Policies}

Motitswe (2012) argues that inclusive policy is a necessary tool to achieve the implementation of inclusive education. Motitswe explains that a strong inclusive policy will prevent learners with disabilities and other special needs from exploitation, violation of their human rights, and unfair discrimination, as well as being denied access quality education. An effective policy of inclusion, Motitswe further argues, helps to generate a strong conducive work environment that can accommodate all categories of people, including individuals with disabilities and other special needs. Naidoo, Reddy, and Dorasamy (2014) concur with this point of view. They point out that from a philosophical standpoint every human being is entitled to quality education and that everyone must be accorded equal opportunity to develop their potential, enjoy recognition, and have their human dignity respected. Naidoo et al. (2014) document the necessary prerequisites for a successful implementation of inclusive education. Among these, they highlight the provision of various forms of support, such as: permitting a flexible curriculum for some pupils, the availability of well trained and prepared special needs education teachers, and the modification of school community cultures to go beyond tolerance to acceptance. Stainback, Stainback, and Jackson (1992) attempt to justify the reasons inclusive education may not have been possible in the past. They point out that, rather than addressing what individual learners with disabilities or those with other special needs were capable of, society was always more pre-occupied with their specific impairments. Stainback et al. (1992) assert that through an inclusive approach to education all children are empowered to learn without referring to their differences. They justify their argument, saying that whatever benefits accrue to members of a society are the heritage of all people, and not solely the individual able-bodied members of that society. Regardless of a person's abilities, every person should be recognized as a full member of the human family. Stainback et al. (1992) conclude by advising that the right to inclusion ought to be recognized, as they believe that persons with disabilities should be seen, heard, and acknowledged at the same time.

It is one thing to say that rights of individuals with disabilities and other special needs should be respected, recognized and given due attention. It is another thing altogether to put this into practice. One factor that must not be taken for granted in the achievement of implementation goals is the attitudes of those charged with the implementation. Positive attitudes may enable implementers to carry out their objectives, while negative attitudes can result in a bottleneck to the implementation of inclusive education for learners with disabilities and other special needs. In Uganda, it is not uncommon to hear people expressing discriminatory views regarding the provision of education for learners with disabilities and other special needs. Some people argue that people with disabilities are hard to assist, therefore they conclude that these categories of people do not deserve any form of support, whether educational or social. These expressions perpetuate negative attitudes.

\subsection{Attitudes and Perceptions}

Hobbs and Westling (1998) argue that teachers who exhibit positive attitudes toward learners with disabilities and other special needs can be effective and are active in supporting the implementation of inclusive education. Hobbs and Westling's views are in line with Mukhopadhyay (2013), as well as Sedibe (2012) who interpret attitude from a psychological standpoint, asserting that negative or positive attitudes are a reflection of how individuals behave towards other individuals.

Starczewska et al. (2012) describe the close link between perceptions and attitudes; the former provide a clue as to how people understand what they see or hear about others, while the latter are indicative of the way people act towards something - often expressed through words or behavior towards those with whom they interact. Mukhopadhyay (2013) adds that perceptions represent subjective experiences and not always reality. This study focuses on both the attitudes and the perceptions of teachers towards the implementation of inclusive education for learners with disabilities and other special needs.

\subsection{Curriculum and Learning Environment in Inclusive Settings}

Every country formulates a school curriculum that reflects its philosophy of education in practical terms. A capitalist state develops a school curriculum that promotes its capitalist ideals, a communist state develops its curriculum to promotes communist ideals, etc. If a country were to develop a curriculum that did not reflect and promote its educational philosophy it would be offering an education that was, in many ways, irrelevant to its national vision, mission, goal, values, destiny, and aspirations. The curriculum, therefore, must to some extent be consumable by all categories of learners, even if they have disabilities or other special needs. The curriculum may be consumed in general form, or in modified or special forms. It should be noted that one of the weaknesses in the implementation of inclusive education for learners with disabilities and other special needs in a country like Uganda is due to the way the curriculum is developed and operated. Since the inception of formal education in Uganda in the early $20^{\text {th }}$ century, the curriculum has been provided in a more general form than not. The curriculum has been (and is still) excessively examination oriented, to the extent that learners are expected to pass and score first class grades in examinations at nearly all levels - primary, lower secondary, and high school levels. Even at university level, the type of curriculum is one that encourages learners to cram facts and regurgitate them during examinations. It is not uncommon to find that in primary or secondary schools all learners registering for leaving examinations pass, scoring first class grades. Interestingly, all stakeholders celebrate this sham academic performance as impressive. Here we have an unfortunate situation in which learners are virtually treated as if they are robots, and the accomplishment is celebrated by society. Schools are simply treated as factories for learners to manufacture facts. This approach to the curriculum renders the majority of learners with disabilities and other special needs at a disadvantage in the consumption of education in Uganda (Okech, 2017). Scholars like Starczewska et al. (2012) argue that it is the responsibility of teachers to review the curriculum provision so as to make inclusive education meaningful for diverse learners and adapt the class practice to meet the academic, social and personal needs of all learners. This proposition is currently unworkable in Uganda. Teachers who train in special needs education do not have the ability and capability to develop and modify the school curriculum - the curriculum is centralized and prescribed for teachers to teach in the way it has been designed and developed. 
Mavuso (2015), Landbrook (2009) and Mukhopadhyay (2013) define an inclusive learning environment as one where there is there is respect for all pupils, irrespective of gender, ethnicity, ability, socioeconomic background, or special educational needs. It is one where the classroom is physically well set up, and which provides a good psychosocial learning environment. It is also a place where there is an adequate provision of elements such as classroom space, classroom infrastructure, arrangement of furniture, class size, classroom display, and resources. Such a conducive environment, the authors believe, provides the necessary benefits desirable for all categories of learners.

\section{Methodology}

This study (conducted between January 2019 and May 2019) adopted a case study design and employed qualitative approaches to sampling. The participants of the study $(\mathrm{N}=103)$ included special needs teachers $(\mathrm{N}=73)$ and learners with disabilities and other special needs $(\mathrm{N}=30)$. The study was conducted in selected primary schools around Kampala Capital City Authority (KCCA). Data collection was carried out by means of interviews. Seventythree surveys were distributed to special needs teachers who expressed an initial interest in participating in the survey, and 30 interviews were carried out with pupils with disabilities. Each teacher received a copy of the survey questionnaire, including a cover letter, which included the consent form for participation and a definition of inclusive education. Each teacher was asked to read and sign the consent form and to return the completed survey questionnaire in a sealed format. Data were analyzed using content and thematic analysis.

\section{Results}

The findings of the present study from the in-depth surveys and interviews revealed that the educators perceived inclusive education as being needful in primary schools and that they were passionate and eager to accommodate or embrace learner diversity. The educators' responses revealed their concern about the inclusivity of learner diversity in their schools and their willingness to fully implement inclusive education to catch up with the requirements of the present education system.

\subsection{The Findings on Inclusive Policies}

The following verbal quote from the interview transcripts reflects the participants' perceptions:

"We have got different learners who learn differently, and schools have to accept and welcome learners who have got different learning barriers. I think that Inclusive Education is necessary because it helps develop individual strengths and gifts for each learner. Indeed, Inclusive Education is essential because we find that it entails all groups of learners, and all learners must be catered for."

Educators believed that discriminating against learners with barriers to learning by sending or referring them to specialist schools was not the best thing to do. Their suggestion was for learners to be enrolled in ordinary schools, with all school stakeholders recognizing and respecting their special needs. The following quotes are representative of the teachers' perceptions:

"I think discriminating against learners with disabilities is not proper because in real life we learn from each other, even though those learners are classified as having special needs, but they do know something that learners who are classified as normal do not know about. It is not good to separate these learners because those with disabilities, whether physically or mentally challenged, will never feel isolated. They will feel that they are like other learners."

"In our school, we are against discrimination of learners with disabilities, and I think we must mix the learners with disabilities with those who do not have disabilities."

\subsection{Attitudes and Perceptions}

Through in-depth interviews in primary schools, educators reported female teachers as having more compassion for children and being more able to identify barriers to learning as they interacted with pupils in the teaching and learning environment. Some teachers reported that male teachers seemed to have more difficulty in this regard. When a learner behaved strangely, they threatened them and could not identify the underlying cause of the child's undesirable behavior. The following verbal quotes support the above findings:

"Female teachers find it easy to identify learners with difficulties, unlike male teachers. I do not know whether I can say, sometimes, male teachers are ignorant or what I think females would be in a better position than males."

"Female educators have the ability and the 'eye' to identify several learners with disabilities, but men are ignorant.

I am sorry to say that (laughing). Females have that compassion for kids and are always able to identify these learners than male educators."

The responses of some teachers during the in-depth interviews indicated that the implementation of inclusive education in the selected primary schools had only been carried out to a lesser extent. One respondent noted,

"Yes, we are doing our best to implement inclusive education. We have got situations whereby we try to identify learners with learning barriers and problems, and then we have tried in our capacity and capability to implement it."

The interview findings also revealed some educators' perceptions about the effectivity of the implementation of the inclusive teaching and learning strategies in their schools. The educators expounded on their efforts to apply or enforce various inclusive teaching strategies in their classroom situations with the aim of accommodating learner diversity. The inclusive teaching and learning strategies that the educators claimed to be using in their classrooms were revealed in their explanations. Examples included peer-tutoring, flexible groupings of learners, designing down and scaffolding, accommodation of learners with visual impairments, and accommodation of ordinary learners. The in-depth interviews further revealed that educators had positive perceptions about supporting learners with behavior problems, especially those who were perceived as hyperactive, who tended to finish writing before the others, and those with bullying behaviors. In these cases, educators reported that they would give the hyperactive pupils advanced activities to keep them busy and remind the bullies of the classroom rules to calm them down, respectively.

It emerged from the in-depth interviews that the educators perceived their lack of training in the area of inclusive education as a challenge. $f$ the teachers who participated in the current study asserted that they were not trained for 
inclusive education and found it difficult to adjust their teaching methods to suit the newly introduced Inclusive Education program. Some educators' interview responses indicated that the lack of training concerning inclusive education is why many educators are reluctant to involve themselves in applying inclusive education teaching strategies in their classroom situations. A participant noted:

"Teachers are trying their best, but as you know, they are not trained; they are still using the old methods, so it is a challenge."

\subsection{Curriculum and Learning Environment in Inclusive Settings}

Despite the level of support strategies offered by a school, e.g., physical adaptations, speech and language support, teaching assistants, select units, and professional help, individual teachers' attitudes were shown to vary between acceptance and rejection. Some teachers felt that children with special needs were not their responsibility and turned inclusion into exclusion by practicing isolation inside the classroom. If schools wish to move towards inclusive schooling, members of the administration team and external school consultants will need to carefully consider the influence of the core values of the local community, as well as the collective values, experiential knowledge, and skills of the school staff, and the traditional values of the school.

Respondents were furthermore asked to list three concerns that they had regarding inclusive education. These open-ended responses were reviewed and coded into nine areas of interest (e.g: subject contents, methods used for teaching, methods used for learning, teaching/learning, materials, physical infrastructure, classroom environment, support from the school, support from donors and interaction amongst learners of different categories):. Those respondents who did not list any concerns were assigned a value of "no" for each of these nine areas of concern. Overall, the respondents indicated the most positivity towards inclusive education on items dealing with student behaviors, and the least positivity on those related to teachers' feelings of competence. Through our interactions with teachers it was revealed that generally the learning environment is supportive of pupils with special needs.

Concerning infrastructure, in three of the primary schools visited the toilets were only suitable for able-bodied children. There were no Braille resources available for children with visual impairment. The physical infrastructure remained as it had been before introducing inclusive education, i.e., there were no ramps or pathways suitable for pupils in a wheelchair. Only one school, which had received earlier support from private donors, had modified toilets and a customized classroom - used as a preparatory class for pupils until they could be placed in inclusive courses. One participant noted:

"In my school, we have got newly constructed building blocks where learners with wheelchairs can freely move, and

even the ramps are there. The only challenge is with the equipment to cater for other disabilities. We have got the

ramps for those learners on wheelchairs and the sanitary system, which is relevant for them, but we do not have the

equipment to help learners with hearing and visual impairments."

Without assistive devices, which are a must for pupils with disabilities, their continued participation is meaningless. What is evident here is the government's lack of constructive action to ensure that the environment is suitable to support all children's learning. These findings generally reflect the societal status of learners with disabilities.

Further difficulties arose when a disability was severe, there was the presence of cognitive delay, or the child's physical appearance was different from other children. One school's headteacher made it clear that the severity of the disability was decisive in determining the school's ability to include the child: "No! They are difficult... Yet, I do not support it (inclusion)... unless it is applied according to the degree of impairment... If the difficulties are severe, it would be better for the pupils to be in a special class."

Mental ability was another factor in the participants' attitudes to the inclusion of children with disabilities. Most of the participants favored inclusion of a child with a physical disability so long as she had an average cognitive ability:

"I do not think that children with any kind of mental disability can be included in the public schools; but those with physical disabilities, such as paralysis and not those with sensory disabilities are the best for inclusion. It only requires the provision of unique approaches, and they do not need any change to be made to the curriculum or the instructions, and they will not be a burden to teachers."

It appears that teachers preferred to include children with physical rather than cognitive disabilities, since these do not require any changes in classroom practice. These quotations, however, reveal that for many respondents, children with physical impairments could be excluded unless they were able to prove that they were mentally able to participate. The only objection to including children with physical disabilities came from a teacher who noted the limitations of their surroundings, without any mention of the child's mental ability:

"I expect the group with physical disabilities to be hard to include... The buildings are not ready yet accommodative for children with special needs."

A child's physical appearance was also shown to limit inclusion; as one teacher observed, a different appearance would naturally lead to exclusion:

“... No! No! It is hard to even for children with physical disabilities...because there is by ordinary pupils laughing and embarrassing questions such as 'Why can't you walk?' will negatively affect the psychology of disabled students."

Many respondents questioned inclusive policies, and in doing so, drew attention to the fact that what often happened in practice was integration, as opposed to inclusion. Inclusion necessitates that teachers change their approaches to suit differing educational needs, but there is a lack of evidence to support that this happens in practice. Teachers, too, seem fully aware that they cannot, in many cases, provide the level of specialist instruction that children with disabilities may require. The overall lack of appropriate training means that in effect teachers treat children with disabilities in their classes as though they were ordinary children.

The integration of ordinary learners with those who have learning disabilities was upheld by teachers who based their opinions on the theory that this would promote corporate or shared learning, and would instill a sense of selfconfidence in learners with disabilities. The following verbal quotes substantiate this:

"Integration is proper because learners can learn from one another in any way. So, I do not think there will be any

problem if they are mixed like that because those learners with disabilities will gain confidence from their ordinary 
peers. It is proper to integrate learners because learners who have some challenges and disabilities when they are included with ordinary ones who are without, will learn from them."

Overall, the in-depth interviews showed that educators perceived their school environments to be unfit for the implementation of inclusive education. The educators raised various issues, such as old school buildings that were unfit to accommodate learners with physical impairments, a lack of facilities and predicaments surrounding service delivery, and a shortage of equipment to assist learners with various other disabilities.

\section{Conclusions and Recommendations}

Based on the study results, the following conclusions can be drawn. In the first place, the policy on the implementation of inclusive education for learners with disabilities and other special needs in Uganda is clear and beneficial to the learners. The challenges faced in the implementation can be attributed to unclear attitudes and perceptions on the part of some policy implementers. The current examination-oriented system of education, which is in place across all levels of education, still poses a challenge to the effective implementation of inclusive education in Uganda. Given such challenges, a review of the school curriculum at the primary level (where this study was focused) is recommended, among other things. A major recommendation would be to draw the attention of policy makers to support inclusive education, which in turn would enable teachers to get more involved in curriculum reforms. The curriculum at primary level should be balanced in terms of academic and practical approaches. Learners with disabilities and other special needs should be supported to learn at their own pace, based on their abilities and capabilities. Examination-oriented systems should be revised. Finally, additional research studies should be carried out on the inclusive education policies in Uganda.

\section{References}

Hobbs, T., \& Westling, D. L. (1998). Promoting successful inclusion through collaborative problem solving. Teaching Exceptional Children, $31(1), 12-19$.

Landbrook, M. (2009). Challenges experienced by educators in the implementation of inclusive education in Primary Schools in South Africa. Unpublished M.Ed. Thesis. Pretoria: University of South Africa.

Louw, B., \& Wium, A. M. (2015). The South African national school curriculum: Implications for collaboration between teachers and speechlanguage therapists working in schools. South African Journal of Childhood Education, 5(1), o1-28.

Mavuso, M. F. (2015). Learning support framework for supporting learners presenting with specific learning difficulties in the senior phase mainstream schools: The University of Johannesburg.

Motitswe, J. M. C. (2012). Teaching and Learning methods in inclusive classrooms in the Foundation Phase. Unpublished M.Ed. Thesis. Pretoria: The University of South Africa.

Mukhopadhyay, S. (2013). Inclusive education for learners with special educational needs in Botswana: Voices of special educators. Gaborone: The University of Botswana.

Naidoo, U., Reddy, K., \& Dorasamy, N. (2014). Reading literacy in primary schools in South Africa: Educator perspectives on factors affecting reading literacy and strategies for improvement. International Journal for Education, 7(1), 155-167.

Okech, J. B. (2017). The praeger international handbook of special education. Book Chapter on Uganda, 1, $254-264$.

Oswald, M., \& Swart, E. (2011). Addressing South African pre-service teachers' sentiments, attitudes, and concerns regarding inclusive education. International Journal of Disability, Development, and Education, 58(4), 389-403.

Richy, D. D., \& Wheeler, J. J. (2016). Inclusive early childhood education. New York: Delmar Publishers.

Samkange, W. (2013). Inclusive education at primary school: "A case study of one primary school in glen view/Mufakose Education District in Harare, Zimbabwe. International Journal of Social Sciences and Education, 3(4), 2223-4934.

Scherman, V., Zimmerman, L., Howie, S. J., \& Bosker, R. (2014). Setting standards and primary school teachers' experiences of the process.

Sedibe, M. (2012). Parental involvement in the teaching and learning of their children in disadvantaged schools. Journal of Social Science, 30(2), $153-159$.

Stainback, S., Stainback, W., \& Jackson, H. J. (1992). Towards inclusive classrooms, curriculum considerations in inclusive classrooms. Baltimore, Baltimore Press.

Starczewska, A., Hodkinson, A., \& Adams, G. (2012). Conceptions of inclusion and inclusive education: A critical examination of teachers' perspectives and practices in Poland. Journal of Research in Special Educational Needs, 12(3), 162-169.

UNESCO. (2013). Education sector technical notes: Inclusive education. unesdoc.unesco.org.

United Nations Educational Scientific and Cultural Organisation (UNESCO). (1994). The salamanca declaration on inclusive education. Paris: UNESCO.

United Nations Girls Education Initiative-UNGEI. (2017). Equity and inclusion guide. Retrieved from: www.ungei.org 